\title{
Flow discharge estimation in compound open channel using theoretical approaches
}

\author{
Abbas Parsaie $^{1} \cdot$ Shadi Najafian $^{1} \cdot$ Hojjatallah Yonesi ${ }^{1}$
}

Received: 12 November 2015 / Accepted: 31 August 2016/Published online: 12 September 2016

(C) Springer International Publishing Switzerland 2016

\begin{abstract}
Estimating the value of discharge in water ways is an important factor in the flood controlling projects. Recently by advances in flood management, investigators have proposed to use the concept of compound section for modeling the flow characteristics in the natural waterways such as rivers. Several conceptual and theoretical approaches based on the idea of compound section have been proposed for estimating the discharge in rivers. In this study, the performances of the theoretical methods were assessed using performing series of experiments in straight prismatic compound open channel and also analyzing the published data in the literature. Analyzing the performance of theoretical methods shows that Divided Channel Method including vertical bounded line with the determination of coefficient (0.91) and root mean square error (0.02) is an accurate method through the theoretical approaches and only this method has suitable ability to apply for practical purposes.
\end{abstract}

Keywords Compound open channel · River discharge . Divided channel method · Flood management

Abbas Parsaie

Abbas_Parsaie@yahoo.com

Shadi Najafian

sh_najafyan@yahoo.com

Hojjatallah Yonesi

yonesi.h@lu.ac.ir

1 Department of Water Engineering, Lorestan University, Khorramabad, Iran

\section{Introduction}

Flow discharge is a basic parameter in developing the water resource projects such as hydro-power systems, irrigation and drainage networks (Chen 2015; Chow et al. 1988). Channels are the main structures which have been used for conveying the water or wastewater in the water engineering projects (Akan 2011; Subramanya 2009). Study on the flow discharge in the open channels has become an important subject in management of water resources; therefore, several researchers have attempted to propose approaches for measurement and estimation of discharge in the open channel (Haghiabi 2012; Heidarpour et al. 2008; Parsaie and Haghiabi 2015a, b, c; Parsaie et al. 2015a, b; Vatankhah 2012, 2013a, b). Calculating the flow discharge in conventional open channels usually is conducted by classical empirical formulas such as Manning and Chezy formulas (Parsaie 2016). These formulas have dependable performance for calculating the discharge in normal channel but when floods occur, surplus flow on the capacity of the normal channel flow in floodplains makes using the classical formulas for estimating the discharge of flow unsure. Using them may lead to errors (Ackers 1993; Al-Khatib et al. 2012, 2013; Azamathulla et al. 2016; Dehdar-behbahani and Parsaie 2016; Parsaie and Haghiabi 2014; Parsaie and Haghiabi 2015a, b, c). Several reasons have been reported for the lack reliability of these methods under flood conditions (Bousmar and Zech 1999). Investigators have tried to modify and improve the performance of these formulas and proposed the concept of compound sections as a novel approach for estimating the discharge of flow especially in natural streams (Hosseini 2004; Huthoff et al. 2008; Parsaie and Haghiabi 2015a, b, c). Figure 1 shows a sketch of the proposed compound section for use in the study on the natural streams. As seen from Fig. 1a 
Fig. 1 Cross section of compound open channel

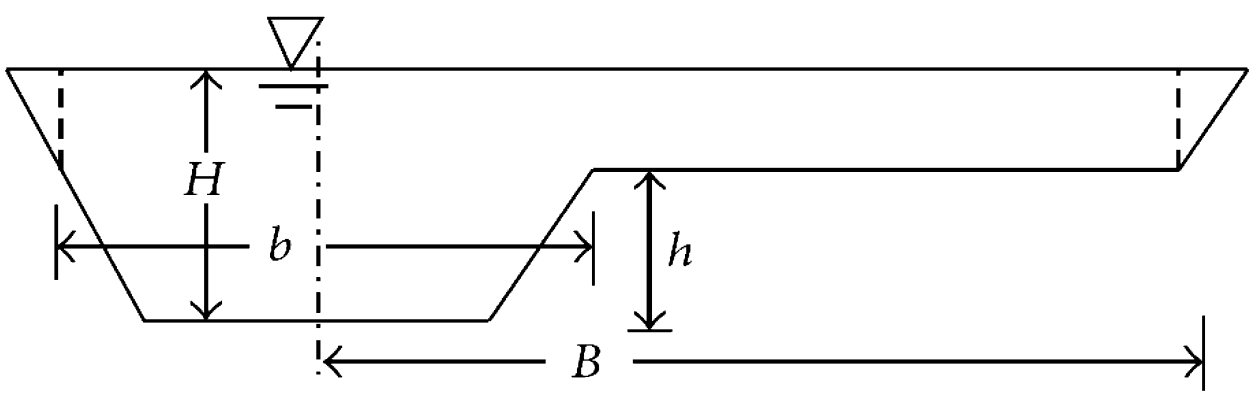

compound section includes a main channel and flood plains. Because of reduction of flow velocity in the floodplains, this part of the cross section is usually covered by vegetation and is rougher than the main channel.

In the Fig. 1 the roughness of the main channel was defined with the $n_{\mathrm{mc}}$ and roughness of the floodplains were introduced by $n_{\mathrm{fp}}$. Flow depth in the main channel characterized by $\mathrm{H}$ and main channel depth was defined by $\mathrm{h}$. Several ways for theoretical methods and soft computing techniques have been proposed for calculating and predicting the flow discharge in compound open channel. In field of theoretical approaches Single Channel Method (SCM) and divided channel method (DCM) as proxy of theoretical methods can be stated (Atabay and Knight 2006; Knight and Demetriou 1983; Knight and Shamseldin 2005; Knight et al. 1984; Liao and Knight 2007; Tang et al. 1999; Unal et al. 2010). In the field of soft computing techniques using the Artificial Neural Networks (ANNs), M5 tree, Genetic Programming (GP), group method of data handling (GMDH) and Support Vector Machine (SVM) can be mentioned (Azamathulla and Zahiri 2012; Noori et al. 2009, 2016; Osooli et al. 2011; Parsaie et al. 2015a, b; Sahu et al. 2011; Unal et al. 2010; Zahiri and Azamathulla 2014). In this study to assess the performance of the most famous empirical approaches, a series of laboratory experiments were programmed and executed in the hydraulic laboratory of Tehran University (Iran). To compare the obtained results from the laboratory experiments with previous studies, 396 datasets related to discharge of flow in compound open channel published in the literature were retrieved and examined.

\section{Materials and method}

The experiments were carried out in a compound open channel in which properties were shown in Fig. 2. As indicated, the longitudinal slope is equal to 0.00088 , the length of channel is about $15 \mathrm{~m}$, bottom with of the main channel is $0.4 \mathrm{~m}$ and the main channel depth is $0.18 \mathrm{~m}$, and with of floodplains are $0.4 \mathrm{~m}$. The cross slope of floodplains are equal to zero. The range of discharge of flow was measured between 0.35 and $0.75\left(\mathrm{~m}^{3} / \mathrm{s}\right)$. The discharge of flow was measured using a calibrated v-notch weir and the flow depth in the main channel and floodplains were recorded using the point gage.

Flow in the compound open channel is a complex phenomenon and there are many influencing parameters on the discharge capacity. The important parameters are given in Eq. (1) including the hydraulic and geometric characteristics:

$Q_{\mathrm{cmp}}=f\left(f_{\mathrm{fp}}, f_{\mathrm{mc}}, A_{\mathrm{fp}}, A_{\mathrm{mc}}, R_{\mathrm{fp}}, R_{\mathrm{mc}}, S, h,(H-h)\right)$,

where $Q_{\mathrm{cmp}}$ is the discharge of the flow in compound open channel, $f_{\mathrm{fp}}$ and $f_{\mathrm{mc}}$ are the roughness of main channel and floodplains, respectively. $A_{\mathrm{fp}}$ and $A_{\mathrm{mc}}$ are the areas of main channel and floodplains, $R_{\mathrm{fp}}$ and $R_{\mathrm{mc}}$ are the hydraulic radius of the main channel and floodplains, $S$ is longitudinal slope of compound open channel, $H$ and $h$ are the depth of flow in the main channel and floodplains, respectively. Sahu et al. (2011) arranged these parameters in a group of dimensionless parameters (Eq. 2) and used them to develop an ANN for predicting the discharge of flow in compound open channel:

$Q=f f_{r}, A_{r}, R_{r}, S, H_{r}$.

In which that $f_{r}$ is defined as $\frac{f_{\mathrm{mc}}}{f_{\mathrm{fr}}}, A_{r}$ is defined as $\frac{A_{\mathrm{mc}}}{A_{\mathrm{fp}}}, R_{r}$ is defined as $\frac{R_{\mathrm{mc}}}{R_{\mathrm{fp}}}$, and $H_{r}$ is defined as $\frac{H-h}{H}$. As mentioned in the introduction section one of the main part of this study is a compression with the results of other researches. To this 396 data set related to the discharge of flow in compound open channel was collected and ranges of them are given in Table 1.

\section{Single channel method (SCM)}

The Single channel method (SCM) considered the cross section of the compound open channel as unique, and there is no difference between the normal and the compound channel. The main point of the SCM is calculating the equivalent roughness for the compound open channel by prevalent methods such as the Horton and the Einstein formulas (Eq. 3), and then the discharge is calculated by 
Fig. 2 Sketch of laboratory model of compound open channel
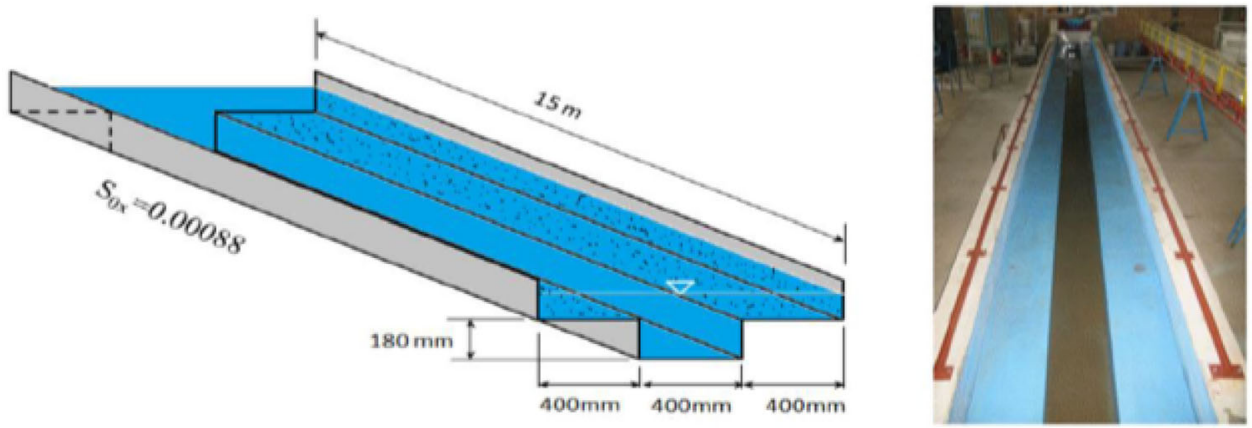

Table 1 Summary of collected data range related to discharge of flow in the compound channel

\begin{tabular}{|c|c|c|c|c|c|c|c|c|c|c|}
\hline References & Range & $H$ & $h$ & $(H-h)$ & $B$ & $b$ & $n(\mathrm{fp})$ & $n(\mathrm{mc})$ & $S$ & $Q(\mathrm{~m})$ \\
\hline \multirow[t]{4}{*}{ Knight et al. (1984) } & Min & 0.085 & 0.08 & 0.009 & 0.15 & 0.08 & 0.0100 & 0.0100 & 0.0010 & 0.0049 \\
\hline & Max & 0.154 & 0.08 & 0.078 & 0.31 & 0.08 & 0.0100 & 0.0100 & 0.0010 & 0.0294 \\
\hline & AVG & 0.112 & 0.08 & 0.036 & 0.23 & 0.08 & 0.0100 & 0.0100 & 0.0010 & 0.0116 \\
\hline & STDEV & 0.022 & 0.00 & 0.022 & 0.06 & 0.00 & 0.0000 & 0.0000 & 0.0000 & 0.0068 \\
\hline \multirow{4}{*}{$\begin{array}{l}\text { Wormleaton and Merrett (1990) (UK } \\
\text { Flood Channel Facility) }\end{array}$} & Min & 0.058 & 0.05 & 0.006 & 0.61 & 0.20 & 0.0091 & 0.0091 & 0.0001 & 0.0100 \\
\hline & Max & 0.302 & 0.15 & 0.152 & 5.00 & 0.75 & 0.0910 & 0.0210 & 0.0020 & 1.1142 \\
\hline & AVG & 0.169 & 0.12 & 0.050 & 2.40 & 0.58 & 0.0220 & 0.0113 & 0.0007 & 0.3230 \\
\hline & STDEV & 0.066 & 0.05 & 0.040 & 1.47 & 0.26 & 0.0239 & 0.0030 & 0.0009 & 0.2946 \\
\hline \multirow[t]{4}{*}{ Tang et al. (1999) } & Min & 0.056 & 0.05 & 0.006 & 0.61 & 0.20 & 0.0056 & 0.0079 & 0.0020 & 0.0130 \\
\hline & Max & 0.220 & 0.05 & 0.170 & 0.61 & 0.20 & 0.0957 & 0.0390 & 0.0020 & 0.2180 \\
\hline & AVG & 0.092 & 0.05 & 0.042 & 0.61 & 0.20 & 0.0346 & 0.0170 & 0.0020 & 0.0499 \\
\hline & STDEV & 0.042 & 0.00 & 0.042 & 0.00 & 0.00 & 0.0228 & 0.0093 & 0.0000 & 0.0546 \\
\hline \multirow[t]{4}{*}{ Atabay and Knight (2006) } & Min & 0.061 & 0.05 & 0.011 & 0.61 & 0.20 & 0.0063 & 0.0091 & 0.0020 & 0.0180 \\
\hline & Max & 0.120 & 0.05 & 0.070 & 0.61 & 0.20 & 0.0112 & 0.0115 & 0.0020 & 0.1830 \\
\hline & AVG & 0.072 & 0.05 & 0.022 & 0.61 & 0.20 & 0.0081 & 0.0098 & 0.0020 & 0.0474 \\
\hline & STDEV & 0.014 & 0.00 & 0.014 & 0.00 & 0.00 & 0.0013 & 0.0006 & 0.0000 & 0.0391 \\
\hline \multirow[t]{4}{*}{ Khatua et al. (2012) } & Min & 0.136 & 0.12 & 0.016 & 0.22 & 0.06 & 0.0100 & 0.0100 & 0.0019 & 0.0087 \\
\hline & Max & 0.223 & 0.12 & 0.103 & 0.22 & 0.06 & 0.0100 & 0.0100 & 0.0019 & 0.0391 \\
\hline & AVG & 0.174 & 0.12 & 0.054 & 0.22 & 0.06 & 0.0100 & 0.0100 & 0.0019 & 0.0212 \\
\hline & STDEV & 0.031 & 0.00 & 0.031 & 0.00 & 0.00 & 0.0000 & 0.0000 & 0.0000 & 0.0111 \\
\hline \multirow[t]{4}{*}{ Ikeda and McEwan (2009) } & Min & 0.207 & 0.20 & 0.007 & 0.81 & 0.28 & 0.0100 & 0.0100 & 0.0001 & 0.0260 \\
\hline & Max & 0.278 & 0.20 & 0.078 & 0.81 & 0.28 & 0.0100 & 0.0100 & 0.0003 & 0.0730 \\
\hline & AVG & 0.242 & 0.20 & 0.042 & 0.81 & 0.28 & 0.0100 & 0.0100 & 0.0002 & 0.0486 \\
\hline & STDEV & 0.018 & 0.00 & 0.018 & 0.00 & 0.00 & 0.0000 & 0.0000 & 0.0001 & 0.0133 \\
\hline \multirow[t]{4}{*}{ Mohanty and Khatua (2014) } & Min & 0.071 & 0.07 & 0.006 & 1.98 & 0.17 & 0.0100 & 0.0100 & 0.0011 & 0.0130 \\
\hline & Max & 0.115 & 0.07 & 0.050 & 1.98 & 0.17 & 0.0100 & 0.0100 & 0.0011 & 0.1062 \\
\hline & AVG & 0.091 & 0.07 & 0.026 & 1.98 & 0.17 & 0.0100 & 0.0100 & 0.0011 & 0.0467 \\
\hline & STDEV & 0.016 & 0.00 & 0.016 & 0.00 & 0.00 & 0.0000 & 0.0000 & 0.0000 & 0.0326 \\
\hline \multirow[t]{4}{*}{ Seckin (2004) } & Min & 0.060 & 0.05 & 0.010 & 0.61 & 0.20 & 0.0090 & 0.0090 & 0.0020 & 0.0148 \\
\hline & Max & 0.168 & 0.05 & 0.118 & 0.61 & 0.20 & 0.0490 & 0.0090 & 0.0020 & 0.0553 \\
\hline & AVG & 0.090 & 0.05 & 0.040 & 0.61 & 0.20 & 0.0288 & 0.0090 & 0.0020 & 0.0299 \\
\hline & STDEV & 0.027 & 0.00 & 0.027 & 0.00 & 0.00 & 0.0177 & 0.0000 & 0.0000 & 0.0117 \\
\hline \multirow[t]{4}{*}{ Wormleaton and Hadjipanos (1985) } & Min & 0.135 & 0.12 & 0.015 & 0.75 & 0.29 & 0.0110 & 0.0099 & 0.0004 & 0.0009 \\
\hline & Max & 0.210 & 0.12 & 0.090 & 0.75 & 0.29 & 0.0210 & 0.0099 & 0.0018 & 0.4800 \\
\hline & AVG & 0.167 & 0.12 & 0.047 & 0.75 & 0.29 & 0.0160 & 0.0099 & 0.0006 & 0.0372 \\
\hline & STDEV & 0.023 & 0.00 & 0.023 & 0.00 & 0.00 & 0.0042 & 0.0000 & 0.0003 & 0.0735 \\
\hline
\end{tabular}


Fig. 3 Types of separating boundary between main channel and floodplains. $a-b$ Vertical, $a-c$ diagonal, $a-a$ horizontal

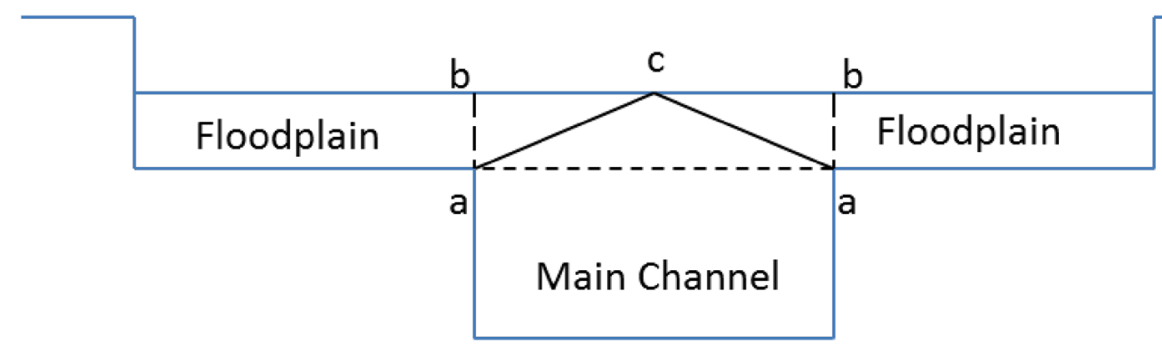

Divided channel method (DCM)

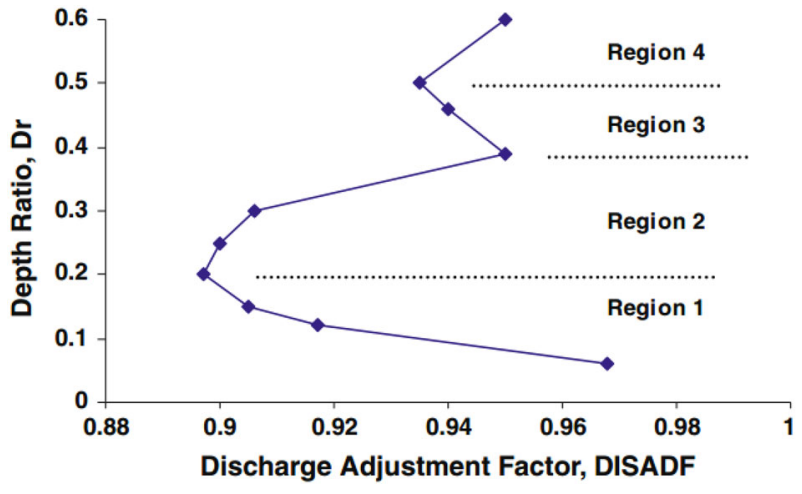

Fig. 4 The diagram of flow discharge adjustment parameter versus relative depth

Eq. (4). The weakness of the SCM is related to the calculation of the transport capacity, especially when the water level increases and the flow covers the floodplains, the wet perimeter increases in comparison with the wet area so the calculated transport capacity is less than the measured data, and at the end, the flow discharge, which is calculated by SCM is less than the actual values. By increasing the flow depth on the floodplains the accuracy of the SCM is improved.

$n_{\mathrm{e}}=\frac{\left[\sum_{i=1}^{N}\left(P_{i} n_{i}^{\frac{3}{2}}\right)\right]^{\frac{2}{3}}}{P^{\frac{2}{3}}}$,

$Q=\frac{1}{n_{\mathrm{e}}} A R^{\frac{2}{3}} S^{\frac{1}{2}}$,

in which the $P_{i}$ is the perimeter of wetted area of the sub section, $n_{i}$ is the Manning's roughness factor for the each sub sections, $P$ is the perimeter of the total flow cross section and $n_{\mathrm{e}}$ is the equivalent roughness (Parsaie et al. 2015a, b).
The Divided channel method (DCM) divides the compound channel into subsections. The DCM is based on the uniform velocity in the area. In this method, the compound channel section is divided into the main channel and the floodplains, and then the total discharge is calculated by adding the discharge through the area. The discharge in the subsections is calculated by Eq. 5. The Manning formula is used for calculating the discharge and the subscription is related to the discharge in each subsections. The separation line between the main channel and the floodplains (Fig. 3) may be considered as vertical, diagonal, or horizontal.

Modifications have been carried out on the Divided Channel Method and in this regard the divided channel method with horizontal separated lines are excluded within the calculation of the wetted perimeter $(\operatorname{DCM}(\mathrm{h}-\mathrm{e}))$. The Divided Channel Method with horizontal separated lines are included within the calculation of the wetted perimeter $(\operatorname{DCM}(\mathrm{h}-\mathrm{i}))$. The Divided Channel Method with vertical separated lines is excluded within the calculation of the wetted perimeter $(\mathrm{DCM}(\mathrm{v}-\mathrm{e}))$. The Divided Channel Method with vertical separated lines which are included within the calculation of the wetted perimeter $(\mathrm{DCM}(\mathrm{v}-\mathrm{i}))$. The divided channel method with bisectional division lines is excluded within the calculation of wetted perimeter $(\operatorname{DCM}(\mathrm{b}-\mathrm{e}))$, and the Divided Channel Method with bisectional division lines is included within the calculation of wetted perimeter(DCM(b-i). A number of commercial software such as HEC RAS, Mike 11 and ISIS have been developed based on the DCM (Atabay and Knight 2006).

$Q_{t}=\left(\sum_{i=1}^{N} \frac{A_{i} R_{i}^{\frac{2}{3}}}{n_{i}}\right) S_{0}^{\frac{1}{2}}$,
Table 2 Results of experiments regards to the Eq. (2)

\begin{tabular}{llllllllll}
\hline Range & $H$ & $h$ & $(H-h)$ & $B$ & $b$ & $n(\mathrm{fp})$ & $n(\mathrm{mc})$ & $S$ & $Q(\mathrm{~m})$ \\
\hline Min & 0.195 & 0.18 & 0.015 & 0.60 & 0.20 & 0.0139 & 0.0139 & 0.0009 & 0.335 \\
Max & 0.333 & 0.18 & 0.153 & 0.60 & 0.20 & 0.0165 & 0.0139 & 0.0009 & 0.682 \\
AVG & 0.257 & 0.18 & 0.077 & 0.60 & 0.20 & 0.0154 & 0.0139 & 0.0009 & 0.511 \\
STDEV & 0.036 & 0.00 & 0.036 & 0.00 & 0.00 & 0.0011 & 0.0000 & 0.0000 & 0.098 \\
\hline
\end{tabular}



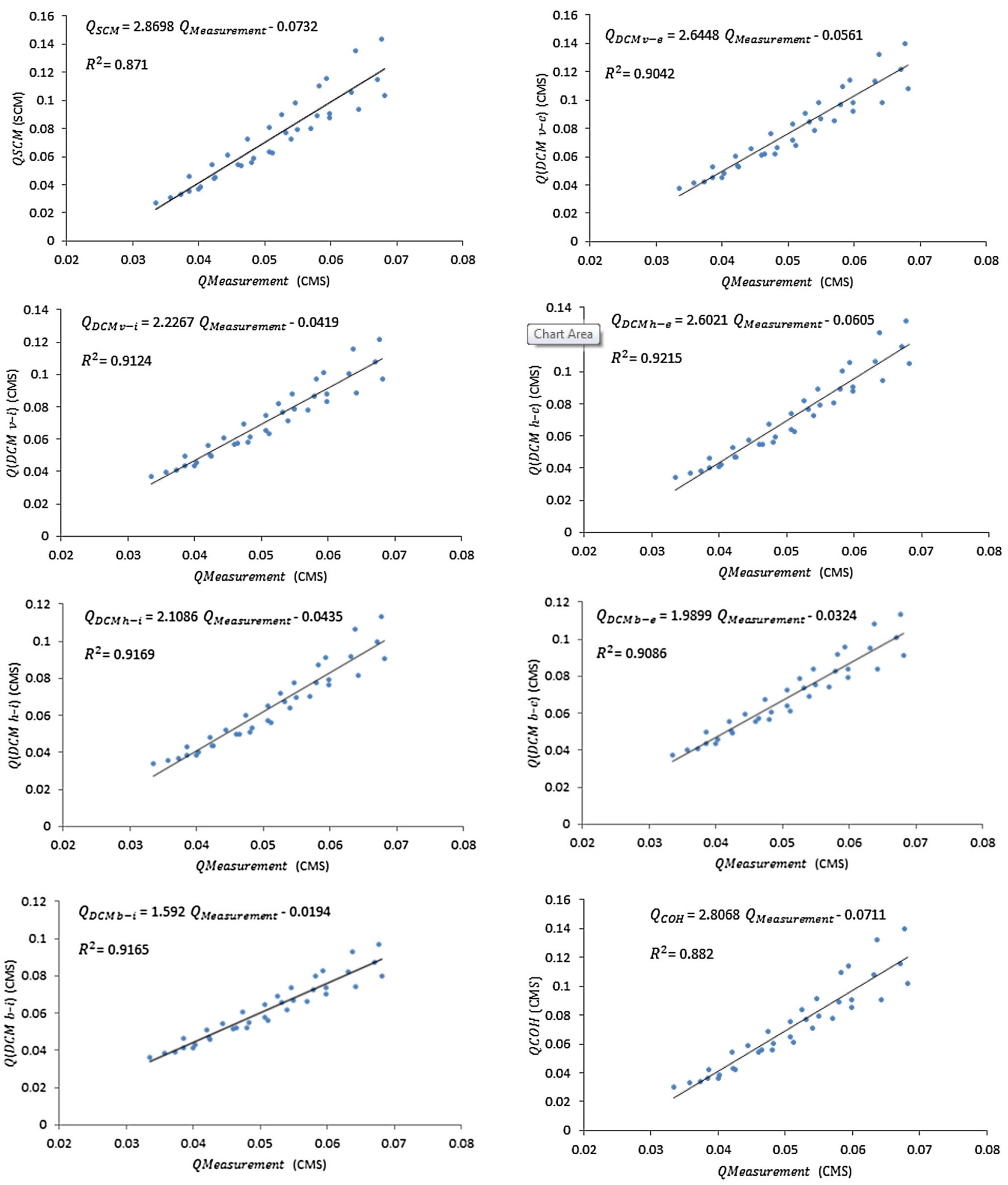

Fig. 5 Correlation between the results of theoretical methods versus the measured data 
Table 3 Performance of theoretical methods for the laboratory experiments

\begin{tabular}{lllrrrr}
\hline Errors & $R^{2}$ & RMSE & \multicolumn{1}{c}{ APE } & \multicolumn{1}{l}{ ER } & MAE & MAPE \\
\hline SCM & 0.87 & 0.03 & 85.63 & -0.11 & 0.02 & 133.16 \\
DCM $_{\mathrm{v}-\mathrm{e}}$ & 0.90 & 0.03 & 109.10 & 0.13 & 0.03 & 145.51 \\
$\mathrm{DCM}_{\mathrm{v}-\mathrm{i}}$ & 0.91 & 0.02 & 105.06 & 0.09 & 0.02 & 132.43 \\
$\mathrm{DCM}_{\mathrm{h}-\mathrm{e}}$ & 0.92 & 0.03 & 98.00 & 0.02 & 0.02 & 132.33 \\
$\mathrm{DCM}_{\mathrm{h}-\mathrm{i}}$ & 0.92 & 0.02 & 94.31 & -0.02 & 0.01 & 117.62 \\
$\mathrm{DCM}_{\mathrm{d}-\mathrm{e}}$ & 0.91 & 0.02 & 105.60 & 0.09 & 0.02 & 128.03 \\
DCM $_{\mathrm{d}-\mathrm{i}}$ & 0.92 & 0.01 & 101.14 & 0.05 & 0.01 & 114.67 \\
$\mathrm{COHM}$ & 0.88 & 0.03 & 86.53 & -0.10 & 0.02 & 131.27 \\
\hline
\end{tabular}

where $A_{i}$ is the area of each subsection, $R_{i}$ is the hydraulic radius of each subsection and $S_{0}$ is the longitudinal slope of compound open channel.

\section{Coherence method (COHM)}

The Coherence method (COHM) is a one dimensional method that was proposed for rectification of the transport capacity parameter in the compound open channel. The COHM is based on the momentum and mass transferring between the main channel and the floodplains. Ackers (1993) proposed a parameter which named the Coherence parameter. As given in Eqs. $(6,7)$ the $\mathrm{COH}$ parameter is defined as a ratio of the transport capacity parameter of $\mathrm{SCM}$ to DCM. If the COH parameter was close to 1 , the compound open channel has hydraulic behaviors similar to the normal channel.

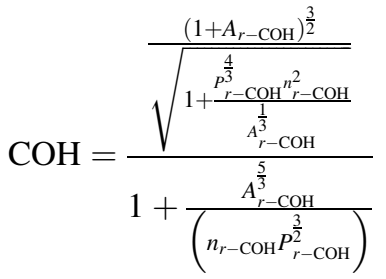

$A_{r-\mathrm{COH}}=\frac{N_{\mathrm{fp}} A_{\mathrm{fp}}}{A_{\mathrm{mc}}}, P_{r-\mathrm{COH}}=\frac{N_{\mathrm{fp}} P_{\mathrm{fp}}}{P_{\mathrm{mc}}}, n_{r-\mathrm{COH}}=\frac{n_{\mathrm{fp}}}{n_{\mathrm{mc}}}$

where $N_{\mathrm{fp}}$ is the number of the floodplains, $A_{\mathrm{fp}}$ is section area of floodplains, $A_{\mathrm{mc}}$ is section area of the main channel, $P_{\mathrm{fp}}$ and $P_{\mathrm{mc}}$ are the wetted perimeters of floodplains and main channel, respectively, fp and mc are the subscription related to the floodplains and the main channel. $\mathrm{COH}$ parameter gets a value between zeros to one. Whenever the
$\mathrm{COH}$ is becoming close to one, the compound channel has a behavior similar to normal channel. Ackers (1993) also proposed a coefficient that he named the Discharge Adjustment Factor (DISADF) used to edit the discharge capacity. The discharge should be corrected based on a value that is derived from Fig. 4 and Eqs. 8 and 9 .

Region 1: $Q_{\mathrm{COH}}=Q_{\mathrm{DCM}}-\mathrm{DISDEF}$,

Region 2, 3 and 4: $Q_{\mathrm{COH}}=$ DISADF $\times Q_{\mathrm{DCM}}$.

\section{Results and discussion}

The ranges of results of experimental parameters regarding the Eq. 2 are given in Table 2. The minimum discharge of flow in experiments which covered the floodplains was equal to $0.335\left(\mathrm{~m}^{3} / \mathrm{s}\right)$ and during the experiments the roughness of main channels were found to be 0.0139 and for floodplains values between 0.0139 and 0.0165 were found. Regarding the derived experimental data the performance of analytical approaches were assessed and are shown in Fig. 5. To carefully assess the accuracy of these methods other error indices such as determination of coefficient $\left(R^{2}\right)$, Root Mean Square Error (RMSE), Relative Error(ER), Absolute Percentage Error (APE), Mean Absolute Percentage Error (MAPE), and Mean Absolute Error (MAE) were calculated and are given in Table 3. It is notable that CMS is cubic meter per second.

Reviewing the Table 3 and Fig. 5 shows that the $\mathrm{DCM}_{\mathrm{v}-\mathrm{i}}, \mathrm{DCM}_{\mathrm{h}-\mathrm{e}}$ and $\mathrm{DCM}_{\mathrm{h}-\mathrm{i}}$ are the most accurate through the analytical approaches and worst accuracy is related to the SCM method. To compare the results with the other previous studies the theoretical methods were assessed using collected data set. The results of evaluating the performance of theoretical methods are given in Fig. 6 and Table 4. Reviewing Table 4 and Fig. 6 shows that the $\mathrm{DCM}_{\mathrm{h}-\mathrm{i}}$ and $\mathrm{DCM}_{\mathrm{v}-\mathrm{i}}$ are the most accurate methods among the empirical approaches. These results ensured the results of experimental runs. The results of this study uphold the results of studies which were conducted by Seckin (2004) and Unal et al. (2010) that stated the accuracy DCM is better than the other empirical formulas. The results of this study also uphold the results of studies which were carried out by Khatua et al. (2012) and Mohanty and Khatua (2014) that proposed a Modified divided channel method for calculating the discharge of flow in compound open channel. 

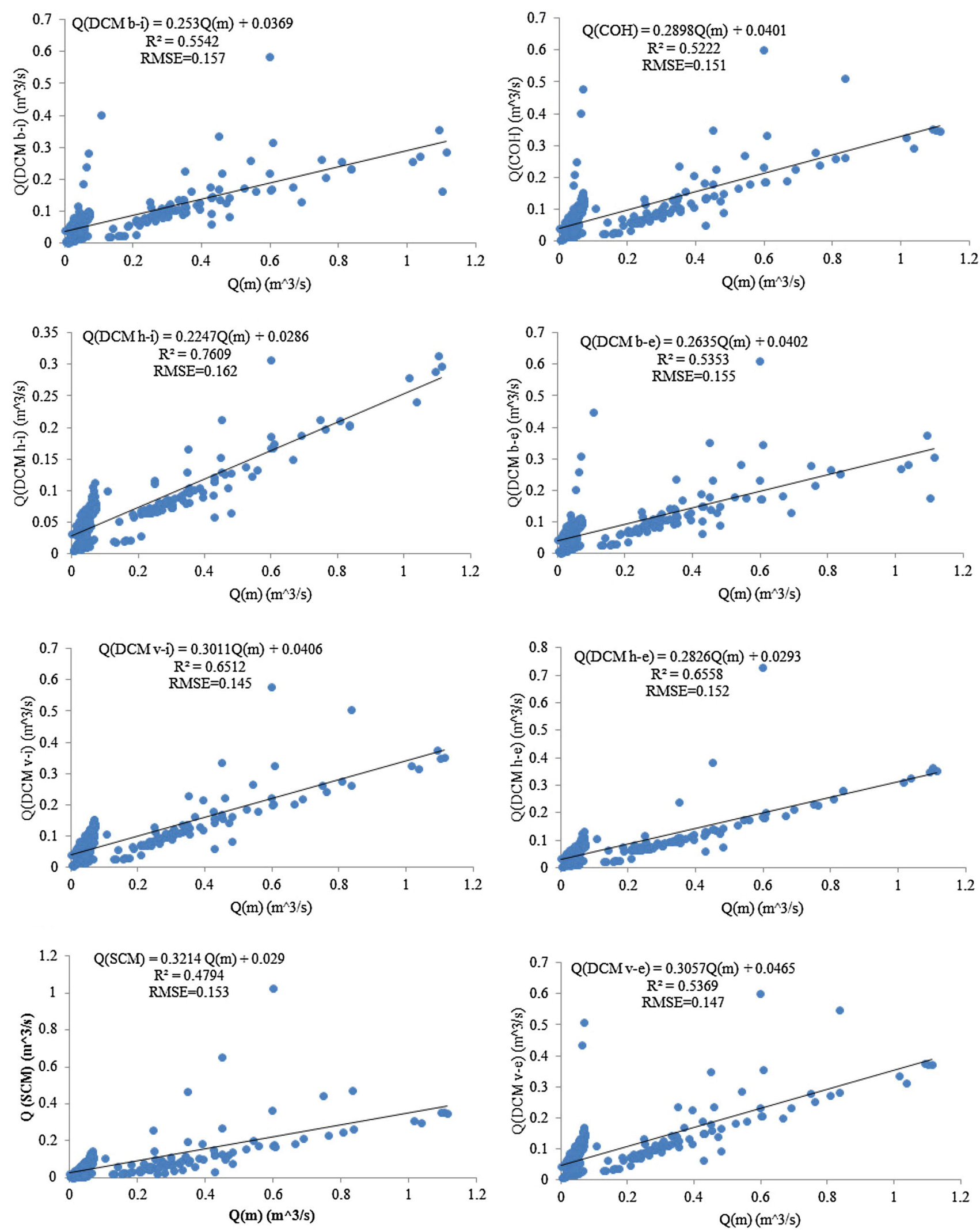

Fig. 6 Correlation between the results of analytical approaches versus the measured discharge (collected data set) 
Table 4 Error indices result of the analytical approaches

\begin{tabular}{llllclr}
\hline Method & $R^{2}$ & RMSE & MAE & APE & MAPE & \multicolumn{1}{c}{$E_{\mathrm{R}}$} \\
\hline SCM & 0.48 & 0.153 & 0.101 & 85.6 & 58.8 & -0.106 \\
DCM $_{\mathrm{v}-\mathrm{e}}$ & 0.54 & 0.147 & 0.093 & 109 & 73.9 & 0.128 \\
$\mathrm{DCM}_{\mathrm{v}-\mathrm{i}}$ & 0.65 & 0.145 & 0.093 & 105 & 68.8 & 0.087 \\
$\mathrm{DCM}_{\mathrm{h}-\mathrm{e}}$ & 0.66 & 0.152 & 0.106 & 86.9 & 45.4 & -0.093 \\
$\mathrm{DCM}_{\mathrm{h}-\mathrm{i}}$ & 0.76 & 0.162 & 0.103 & 94.3 & 58.8 & -0.019 \\
$\mathrm{DCM}_{\mathrm{d}-\mathrm{e}}$ & 0.53 & 0.155 & 0.099 & 105.6 & 65.9 & 0.093 \\
$\mathrm{DCM}_{\mathrm{d}-\mathrm{i}}$ & 0.55 & 0.637 & 0.099 & 101.1 & 60.8 & 0.048 \\
$\mathrm{COHM}$ & 0.52 & 0.151 & 0.097 & 86.5 & 64.9 & -0.097 \\
\hline
\end{tabular}

\section{Conclusion}

The results of this study showed that the classical formula for calculating the discharges of flow in compound open channel has no suitable performance. Therefore, modifications of these formulas are inescapable. The divided channel section is the accurate approach which has suitable performance for calculating the discharge of flow in compound open channel. The results of this study show that assuming the vertical separated boundary line in the divided channel method for individualizing the subsections increases the performance of estimating the discharge of flow.

\section{References}

Ackers P (1993) Flow formulae for straight two-stage channels. J Hydraul Res 31(4):509-531

Akan AO (2011) Open channel hydraulics. Elsevier Science

Al-Khatib IA, Dweik AA, Gogus M (2012) Evaluation of separate channel methods for discharge computation in asymmetric compound channels. Flow Meas Instrum 24:19-25

Al-Khatib I, Hassan H, Abaza K (2013) Application and validation of regression analysis in the prediction of discharge in asymmetric compound channels. J Irrig Drain Eng 139(7):542-550

Atabay S, Knight DW (2006) 1-D modelling of conveyance, boundary shear and sediment transport in overbank flow. J Hydraul Res 44(6):739-754

Azamathulla HM, Zahiri A (2012) Flow discharge prediction in compound channels using linear genetic programming. J Hydrol 454-455:203-207

Azamathulla HM, Haghiabi AH, Parsaie A (2016) Prediction of side weir discharge coefficient by support vector machine technique. Water Sci Technol Water Supply 16(4):1002-1016

Bousmar D, Zech Y (1999) Momentum transfer for practical flow computation in compound channels. J Hydraul Eng 125(7): 696-706

Chen SH (2015) Hydraulic Structures. Springer, Berlin Heidelberg

Chow VT, Maidment DR, Mays LW (1988) Applied hydrology. McGraw-Hill

Dehdar-behbahani S, Parsaie A (2016) Numerical modeling of flow pattern in dam spillway's guide wall. Case study: Balaroud dam, Iran. Alex Eng J 55(1):467-473
Haghiabi AH (2012) Hydraulic characteristics of circular crested weir based on Dressler theory. Biosyst Eng 112(4):328-334

Heidarpour M, Habili JM, Haghiabi AH (2008) Application of potential flow to circular-crested weir. J Hydraul Res 46(5):699-702

Hosseini SM (2004) Equations for discharge calculation in compound channels having homogeneous roughness. Iran J Sci Technol Trans B Eng 28(B5):537-546

Huthoff F, Roos P, Augustijn D, Hulscher S (2008) Interacting divided channel method for compound channel flow. J Hydraul Eng 134(8):1158-1165

Ikeda S, McEwan IK (2009) Flow and sediment transport in compound channels: the experience of Japanese and UK research. Taylor \& Francis, Boca Raton

Khatua K, Patra K, Mohanty P (2012) Stage-discharge prediction for straight and smooth compound channels with wide floodplains. J Hydraul Eng 138(1):93-99

Knight D, Demetriou J (1983) Flood plain and main channel flow interaction. J Hydraul Eng 109(8):1073-1092

Knight D, Shamseldin A (2005) River basin modelling for flood risk mitigation. CRC Press, The Netherlands

Knight DW, Demetriou JD, Hamed ME (1984) Stage discharge relationships for compound channels. In: Smith KVH (ed) Channels and channel control structures. Springer, Berlin, pp 445-459

Liao H, Knight D (2007) Analytic stage-discharge formulas for flow in straight prismatic channels. J Hydraul Eng 133(10): 1111-1122

Mohanty PK, Khatua KK (2014) Estimation of discharge and its distribution in compound channels. J Hydrodyn Ser B 26(1):144-154

Noori R, Abdoli MA, Farokhnia A, Abbasi M (2009) Results uncertainty of solid waste generation forecasting by hybrid of wavelet transform-ANFIS and wavelet transform-neural network. Expert Syst Appl 36(6):9991-9999

Noori R, Deng Z, Kiaghadi A, Kachoosangi FT (2016) How Reliable Are ANN, ANFIS, and SVM techniques for predicting longitudinal dispersion coefficient in natural rivers? J Hydraul Eng 142(1):04015039

Osooli N, Hosseini M, Hosseini JF, Haghiabi AH (2011) A survey: factors affecting the sustainable water recourses management (SWRM) in agriculture under drought conditions in Lorestan, Iran. World Appl Sci J 12(4):476-484

Parsaie A (2016) Analyzing the distribution of momentum and energy coefficients in compound open channel. Model. Earth Syst Environ 2(1): 1-5

Parsaie A, Haghiabi A (2014) Predicting the side weir discharge coefficient using the optimized neural network by genetic algorithm. Sci J Pure Appl Sci 3(3):103-112

Parsaie A, Haghiabi A (2015a) The effect of predicting discharge coefficient by neural network on increasing the numerical modeling accuracy of flow over side weir. Water Resour Manag 29(4):973-985

Parsaie A, Haghiabi A (2015b) Predicting the longitudinal dispersion coefficient by radial basis function neural network. Model Earth Syst Environ 1(4):1-8

Parsaie A, Haghiabi AH (2015c) Computational modeling of pollution transmission in rivers. Appl Water Sci 1-10. doi:10. 1007/s13201-015-0319-6

Parsaie A, Haghiabi AH, Moradinejad A (2015a) CFD modeling of flow pattern in spillway's approach channel. Sustain Water Resour Manag 1(3):245-251

Parsaie A, Yonesi HA, Najafian S (2015b) Predictive modeling of discharge in compound open channel by support vector machine technique. Model Earth Syst Environ 1(1-2):1-6 
Sahu M, Khatua KK, Mahapatra SS (2011) A neural network approach for prediction of discharge in straight compound open channel flow. Flow Meas Instrum 22(5):438-446

Seckin G (2004) A comparison of one-dimensional methods for estimating discharge capacity of straight compound channels. Can J Civ Eng 31(4):619-631

Subramanya K (2009) Flow in open channels. Tata McGraw-Hill, New York

Tang X, Knight DW, Samuels PG (1999) Variable parameter Muskingum-Cunge method for flood routing in a compound channel. J Hydraul Res 37(5):591-614

Unal B, Mamak M, Seckin G, Cobaner M (2010) Comparison of an ANN approach with 1-D and 2-D methods for estimating discharge capacity of straight compound channels. Adv Eng Softw 41(2):120-129

Vatankhah A (2012) New solution method for water surface profile along a side weir in a circular channel. J Irrig Drain Eng 138(10):948-954
Vatankhah A (2013a) Water surface profiles along a rectangular side weir in a U-shaped channel (Analytical Findings). J Hydrol Eng 18(5):595-602

Vatankhah AR (2013b) Water surface profile along a side weir in a parabolic channel. Flow Meas Instrum 32:90-95

Wormleaton PR, Merrett DJ (1990) An improved method of calculation for steady uniform flow in prismatic main channel/ flood plain sections. J Hydraul Res 28:157-174. doi:10.1080/ 00221689009499084

Wormleaton P, Hadjipanos P (1985) Flow distribution in compound channels. J Hydraul Eng 111(2):357-361. doi:10.1061/ (ASCE)0733-9429(1985)111:2(357)

Zahiri A, Azamathulla HM (2014) Comparison between linear genetic programming and M5 tree models to predict flow discharge in compound channels. Neural Comput Appl 24(2):413-420 